\title{
The new treatment approach in knee osteoarthritis: Efficacy of cellular matrix combination of platelet rich plasma with hyaluronic acid versus two different types of hyaluronic acid (HA)
}

Osteoarthritis pathogenesis is a complex process associated with decreased ability to regenerate cartilage mainly due to lack of physiological vascularization. One of the most commonly affected joints is the knee.

Purpose: The aim of this study was to compare the efficacy of intra-articular (IA) injections of platelet rich plasma (PRP) combined with hyaluronic acid (HA) prepared with the Cellular Matrix device versus IA injections with two different types of hyaluronic acid for treatment of knee osteoarthritis.

Material and methods: This is a prospective, randomized, double-blind, controlled study on 53 patients (90 knees) suffering from knee osteoarthritis, divided in 3 groups. The first group comprised 19 patients (30 knees) treated with 3 IA injections, one every second week, of Cellular Matrix (CM) PRP-HA combination. The second group of 19 patients (30 knees) was treated with 3 weekly IA injections of $2 \%$ noncross-linked sodium hyaluronate (ArthroVisc ${ }^{\circ}, \mathrm{AV}$ ) and the third group of 15 patients (30 knees) treated with 3 weekly IA injections of $2 \%$ non-cross-linked sodium hyaluronate with mannitol (Ostenil ${ }^{\circ}$ Plus, OP). All groups were homogeneous concerning gender, age and Kellgren Lawrence scale (I to III). For all patients visual analog pain scale (VAS), Western Ontario and McMaster Universities Osteoarthritis Index (WOMAC), Knee Injury and Osteoarthritis Outcome Score (KOOS), The International Knee Documentation Committee (IKDC) score ("well-being" scale for all 4 scores between 0 and 100) and ultrasound (US) cartilage thickness on lateral, trochlear, and medial compartments, with normal range values from 2 to $2.5 \mathrm{~mm}$, were measured at the beginning of the treatment (baseline) and at each follow up visit, that is at 2, 6 and 12 months after the last injection.

Results: A statistically significant difference $(p<0.05)$ in the $C M$ group was found compared to AV and OP group in the values of VAS, WOMAC, KOOS and IKDC after two months, although an improvement, compared to baseline values, was observed for the indicated parameters in all groups. A high statistically significant difference $(p<0.01)$ was obtained in the CM group compared to the AV and OP group for VAS, WOMAC, KOOS and IKDC after 6 and 12 months. In both groups of patients treated with hyaluronic acid, a deterioration of values for VAS, WOMAC, KOOS and IKDC score was seen at 12 months in relation to values at 6 months. The $C M$ treated group showed statistically significant improvement $(p<0.05)$ of the cartilage thickness after 2, 6 and 12 months in the medial and highly statistically significant improvement $(p<0.01)$ in the lateral segments of knee cartilage in comparison to baseline values.

Conclusion: The Cellular Matrix PRP-HA combination (CM-PRP-HA) might be one of the most potent, safe, fast and novel therapeutic option for osteoarthritis of the knee (Kellgren-Lawrence grade I to III), as well as a useful tool for postponing arthroplasty surgery when it is necessary. For further investigations, we need larger prospective double-blind studies with MRI quantification of CM-PRP-HA effects on cartilage. Taking all this in consideration we are very close to believe that the future therapeutic option for osteoarthritis, will be combining therapeutic effects of Cellular Matrix CM-PRP-HA with bone marrow mesenchymal stem.

Keywords: cellular matrix $•$ platelet rich plasma $\bullet$ hyaluronic acid $\bullet$ knee osteoarthritis $\cdot$ regenerative medicine

\section{Introduction}

Osteoarthritis (OA) pathogenesis is a complex process associated with decreased ability to regenerate cartilage mainly due to lack of physiological vascularization. One of the most commonly affected joints is the knee $[1,2]$. Although OA is a disease of the entire joint (cartilage, ligaments, synovium, and bone), the initial lesion is usually in the articular cartilage.

\section{Branko Barac ${ }^{*}$, Nemanja} Damjanov \& Ana Zekovic Institute for Rheumatology, Belgrade, Serbia

*Author for correspondence: baracbranko3@gmail.com 
OA has a strong genetic component and, in most cases, has mechanical overload as an initiator of the process of cartilage damage, which evolves to a vicious inflammatory cycle, perpetuating joint degradation. This inflammatory pathway has as its primary agents, Interleukin-1 (IL-1) and Tumor Necrosis Factor (TNF), which induce increased expression of metalloproteinases and Nitric Oxide (NO), the main catabolic agents produced by chondrocytes in response to injury, in addition to more IL-1. Therefore, the treatment of osteoarthritis should target both the mechanical overload that leads to joint damage, for example with visco-supplementation with hyaluronic acid, and the inflammatory cycle that perpetuates the injury at one or more points in this chain, with treatments such as corticosteroid IA injections. In the treatment of knee osteoarthritis, many pharmacological and non-pharmacological therapeutic procedures have been used thus far $[3,4]$. Currently, the use of corticosteroids is still necessary in order to address secondary inflammation, as well as to prepare the knee joint for further therapy after arthrocentesis and evacuation of synovial fluid [5]. HA is one of the main components of synovial fluid. It ameliorates absorption during impact as well as lubrication of the joints. HA molecular weight and concentration, are reduced in synovial fluid from patients suffering from osteoarthritis (OA). Twenty-five years of clinical experience with numerous studies have shown pain reduction and functional improvement of knee OA following IA HA injections lasting up to 6 months on average. The mechanism of action is both biomechanical and biological, including anti-inflammatory effects. The network of HA chains forms a perfect matrix for cells [6]. Intraarticular injections of hyaluronic acid have had an effect on reducing the discomfort and slowing down the progression of the disease itself, along with the improvement of viscoelasticity, but have been unable to make possible regeneration of cartilage $[7,8]$.

Biological, regenerative, minimally invasive therapy, such as the one with PRP, has been researched in many studies [9,10]. PRP, with its growth factors can stimulate cartilage reparation, normalize viscoelasticity of synovial fluid, reduce pain, improve the joint function and improve the quality of life $[10,11]$. Activated and concentrated platelets release a large amount of different growth factors from their alpha granules, such as: PDGF (plated derived growth factor) which stimulates cell growth, generation and repair of blood vessels, and production of collagen, TGF- beta (transforming growth factor beta) which stimulates cell proliferation, promotes production of extracellular matrix, stimulates angiogenesis and healing of wounds, VEGF (vascular endothelial growth factor) which stimulates proliferation and migration of endothelial cells, FGF (fibroblast growth factor) which stimulates proliferation, EGF (epidermal growth factor) which stimulates angiogenesis, regulates fluctuation of the extracellular matrix, stimulates proliferation and migration of fibroblasts, IGF (insulin like growth factor) which stimulates cell proliferation, accelerates synthesis of collagen, and stimulates the migration of fibroblasts. The active secretion of these growth factors is initiated by platelet contact with the extracellular matrix. Once secreted, growth factors induce different signal cascades in cells that activate cell proliferation, differentiation and synthesis of the new matrix for tissue regeneration. Numerous in vitro studies have demonstrated the influence of isolated growth factors on chondrogenic stimulation and differentiation of mesenchymal stem cells [12]. In addition, it has been shown that PRP has a significant role in the treatment of soft and hard tissues, with a key effect on cellular migration, proliferation and differentiation [13]. The idea of combining PRP with HA was based on their possible synergistic therapeutic effect in osteoarthritis. With that goal in mind, some in vitro studies have been carried out. Their synergism and positive metabolic balance have been proven in the work from 2014 of Wei-Hong Chen and associates, where the in vitro model has schematically shown the molecular mechanism of chondrogenesis, enhanced by PRP-HA treatment combination. The HA and PRP cooperatively activated surface receptors that triggered release of signaling molecules and finally enhanced chondrogenesis in human articular chondrocyte [14]. Taking into consideration all the aforementioned, it is reasonable to consider the use of a combination of PRP and HA in the treatment of osteoarthritis. Cellular Matrix is the first and the only device on the mark et allowing the combination of PRP with HA in conformity with regulations and good practice.

The aim of this study was to compare the efficacy of IA injections of PRP combined with HA, prepared with the Cellular Matrix device, versus two different types of HA IA injections in the treatment of knee osteoarthritis.

\section{Methods}

\section{Study design and participants}

This is a prospective, randomized, doubleblind, controlled study on 53 patients (90 knees) 


\section{The new treatment approach in knee osteoarthritis: Efficacy of Research Article cellular matrix combination of platelet rich plasma with hyaluronic acid versus two different types of hyaluronic acid (HA)}

suffering from knee osteoarthritis divided in 3 groups. The first group (CM) comprised $19 \mathrm{pa}$ tients (30 knees) treated with 3 IA injections, one every second week, of around $5 \mathrm{ml}$ of CMPRP-HA combination. The second group (AV) of 19 patients (30 knees) was treated with 3 weekly IA injections of $2 \mathrm{ml}$ of $2 \%$ non-crosslinked sodium hyaluronate (ArthroVisc ${ }^{\circ}$ ) and the third group (OP) of 15 patients (30 knees) was treated with 3 weekly IA injections of $2 \mathrm{ml}$ of $2 \%$ non-cross-linked sodium hyaluronate combined with mannitol (Ostenil ${ }^{\circ}$ Plus). All groups were homogeneous concerning gender, age and Kellgren-Lawrence score. Clinical examination and recruitment of participants were conducted at the Institute of Rheumatology, Belgrade Serbia in the period from February 2016 to June 2017. All patients were informed concerning the method and methodology of the study and all of them voluntarily filled out the information consent.

For all patients visual analog pain scale (VAS), Western Ontario and McMaster Universities Osteoarthritis Index (WOMAC), Knee Injury and Osteoarthritis Outcome Score (KOOS) and The International Knee Documentation Committee (IKDC) score ("well-being" scale for all 4 scores between 0 and 100) and ultrasound cartilage thickness on lateral, trochlear, and medial compartments, with normal range values from 2 to $2.5 \mathrm{~mm}$, were measured at each visit. Patients were evaluated before the first injection, and then, two, six and twelve months after the last injection. Routine laboratory tests, including blood platelet count, were performed before each injection.

\section{Treatment protocol}

The Cellular Matrix (CM) A-CP HA Kit (Regen Lab SA, Le Mont sur Lausanne, Switzerland) is a Class III medical device (European classification). CM has been specifically approved for the single step preparation, from a small sample of patient's blood, of autologous PRP in presence of HA in a sterile closed-circuit system. The CM device is an evacuated tube in which the patient blood sample $(6 \mathrm{ml})$ is automatically collected. The blood-filled tube is centrifuged for $5 \mathrm{minu}-$ tes at a relative centrifugal force of $1500 \mathrm{~g}$ (following the manufacturer's instructions), which corresponds to a speed of $3600 \mathrm{spin} /$ minute in our centrifuge model. Thanks to the Regen Lab separating gel technology, the platelets and plasma are isolated from the other blood components and combined with the HA solution pre- sent in the device. The resulting CM-PRP-HA consists of around $3 \mathrm{ml}$ of autologous PRP, with a platelet concentration 1.5 to 1.6 times higher than the baseline value in venous blood and with a low contamination in red and white blood cells (neutrophil poor PRP), entrapped in a 3D network of HA. The device contains $2 \mathrm{ml}$ of natural, non-cross-linked, HA at a concentration of $20 \mathrm{mg} / \mathrm{ml}$ (40 $\mathrm{mg}$ in total). The HA is produced by bacterial fermentation, thus devoid of animal proteins.

CM is approved for both orthopedic and dermal applications in Europe, and clinical studies are ongoing in the US to obtain FDA premarket approval.

The CM Group was treated by a series of 3 CM-PRP-HA injections, one injection every two weeks. Each Injection consisted of around $5 \mathrm{ml}$ of the combination of PRP $(3 \mathrm{ml})$ and HA ( $2 \mathrm{ml}, 2 \%$ non-cross-linked), prepared with the Cellular Matrix device.

The IA injection (US guided, lateral aspect of suprapatellar recess), while patient was laying on the back with legs in full extension) of the CMPRP-HA combination was performed just a few minutes after its preparation in the same room, with all aseptic precautions during the entire procedure. The overall procedure is simple, easy and relatively short, typically lasting less than 20 minutes.

The second Group (AV) was treated by a series of 3 weekly injections of $2 \mathrm{ml}$ of ArthroVisc ( $2 \%$ non-cross-linked HA, $40 \mathrm{mg} / 2 \mathrm{ml}$, Regen Lab SA, Le Mont sur Lausanne, Switzerland). The IA injection was US guided with the same patient position and needle application route, with all aseptic precautions during the entire procedure.

The third Group (OP) was treated by series of 3 weekly injections of $2 \mathrm{ml}$ of OSTENIL PLUS (2\% non-cross-linked HA with mannitol, $40 \mathrm{mg} / 2 \mathrm{ml}$, TRB Chemedica, Switzerland). The same IA injection procedure was applied as for the second group.

Blood sample was taken from each patient before the treatments. Each injection was administrated under sonography control, by the same sonographer. Patient was blinded for the treatment option. An independent rheumatologist, blinded for the treatment option, examined the patients and measured the cartilage thickness by US at each visit. 
Inclusion criteria were age above 30 years and below 80 years, history (at least 4 months) of chronic pain or swelling of the knee, imaging findings of degenerative changes of the joint (Kellgren-Lawrence Score up to 3 at X-ray evaluation, or US findings of degenerative changes (in patients with no $\mathrm{OA}$ signs visible with $\mathrm{X}$-ray), and VAS score larger than 50. Exclusion criteria were age lower than 30 and above 80 years, KellgrenLawrence score higher than 3, systemic diseases such as rheumatoid arthritis, systemic lupus erythematosus etc., major axial deviation (varus $>5^{\circ}$, valgus $>5^{\circ}$ ), history of HA IA treatment, hematological diseases (coagulopathy), severe cardiovascular diseases, infections, immuno-depression, patients in therapy with anticoagulants or aggregation inhibitors, use of NSAIDs in the 5 days before blood donation. Patients with hemoglobin values $<11 \mathrm{~g} / \mathrm{dl}$ and platelet values < $150,000 / \mathrm{mm}^{3}$, patients with corticoid treatment in past 2 months, symptomatic coxarthrosis on ipsi- or contra-lateral side, any hip or knee surgery planned within 6 months, patients showing past allergic reactions to one of the tested components, patients with serious cardiovascular pathologies, with active gastro duodenal ulcers, digestive hemorrhages, hepatic impairment and pregnant or breast feeding women were also excluded.

\section{Statistical analyses}

Results were reported as mean and range of values and presented in tables and charts. Differences between groups and in the same group were assessed by Student's t test and T par test as well as ANOVA. Interobserver correlation coefficient was also used. Differences were considered statistically significant at $\mathrm{p}<0.05$. SPSS 20.0 software was used for the statistical analysis.

\section{Results}

In total 53 patients (90 knees) were examined. The follow up period was up to 12 months after the last injection. Visits were organized at 2, 6 and 12 months after the last IA injection. In Table 1, demographic data as well as body mass index and Kellgren-Lawrence score for all three groups are shown. In Table 2, all measured scores (VAS, WOMAC, IKDC and KOOS) for the Cellular Matrix Group are summarized with values at baseline and at 2, 6 and 12 months after the last injection. Tables 3 and 4 report the scores, at the same time points, for AV and OP groups, respectively.

Figure 1 shows that there were no statistically significant differences for: VAS, WOMAC,

\begin{tabular}{|c|c|c|c|}
\hline & $\begin{array}{l}\text { Cellular } \\
\text { matrix } \\
(n=30)\end{array}$ & $\begin{array}{c}\text { ArthroVisc } \\
(n=30)\end{array}$ & $\begin{array}{c}\text { Ostenil } \\
\text { Plus } \\
(n=30)\end{array}$ \\
\hline Gender, F:M (\%) & $\begin{array}{c}16(53): \\
14(47)\end{array}$ & $\begin{array}{c}17 \text { (57): } 13 \\
(43)\end{array}$ & $\begin{array}{c}17 \text { (57): } 13 \\
(43)\end{array}$ \\
\hline $\begin{array}{l}\text { Age, mean } \pm S D \\
\quad \text { (range) }\end{array}$ & $\begin{array}{c}61.3 \pm 10.9 \\
(39-80)\end{array}$ & $\begin{array}{c}61.3 \pm 10.9 \\
(39-80)\end{array}$ & $\begin{array}{c}66.2 \pm 6.8 \\
(55-78)\end{array}$ \\
\hline $\begin{array}{c}\text { Kellgren- } \\
\text { Laurence grade } \\
\text { 1:2:3 (\%) }\end{array}$ & $\begin{array}{l}10(33): 12 \\
(40): 8(27)\end{array}$ & $\begin{array}{l}12(40): 10 \\
\text { (33): } 8(27)\end{array}$ & $\begin{array}{c}11(36): 8 \\
(27): 11 \\
(37)\end{array}$ \\
\hline
\end{tabular}

\section{Table 2. Group 1 (Cellular Matrix, CM), all scores.}

\begin{tabular}{|c|c|c|c|c|}
\hline $\begin{array}{l}\text { Cellular } \\
\text { matrix }\end{array}$ & Baseline & $\begin{array}{c}\text { After } 2 \\
\text { months }\end{array}$ & $\begin{array}{c}\text { After } 6 \\
\text { months }\end{array}$ & $\begin{array}{l}\text { After } 12 \\
\text { months }\end{array}$ \\
\hline VAS & $\begin{array}{c}75.8(50- \\
90)\end{array}$ & $\begin{array}{c}28.3(0- \\
60)\end{array}$ & $\begin{array}{c}16.4(0- \\
50)\end{array}$ & $17.2(0-50)$ \\
\hline WOMAC & $\begin{array}{c}42.5(14.4- \\
82.6)\end{array}$ & $\begin{array}{c}75 \text { (43.9- } \\
100)\end{array}$ & $\begin{array}{c}83.4(66.7- \\
94.7)\end{array}$ & $\begin{array}{c}82.4(64.2 \\
100)\end{array}$ \\
\hline IKDC & $\begin{array}{c}28(14.9- \\
57.5)\end{array}$ & $\begin{array}{c}57.1(23- \\
94.3)\end{array}$ & $\begin{array}{c}67.7(43.7- \\
90.8)\end{array}$ & $\begin{array}{c}66.2(42.9 \\
90.2)\end{array}$ \\
\hline KOOS & $\begin{array}{c}38.5(9.5- \\
70.8)\end{array}$ & $\begin{array}{c}70.4 \\
(46.4-100)\end{array}$ & $\begin{array}{c}80.8(62.5- \\
94.6)\end{array}$ & $\begin{array}{c}80.2(61.9- \\
93.6\end{array}$ \\
\hline
\end{tabular}

\begin{tabular}{|c|c|c|c|c|}
\hline Arthrovis & c Baseline & $\begin{array}{l}\text { After } 2 \\
\text { months }\end{array}$ & $\begin{array}{c}\text { After } 6 \\
\text { months }\end{array}$ & $\begin{array}{l}\text { After } 12 \\
\text { months }\end{array}$ \\
\hline VAS & $\begin{array}{c}70.2(50- \\
90)\end{array}$ & $46.9(0-90)$ & $\begin{array}{c}56.2(20- \\
95)\end{array}$ & $\begin{array}{c}62.4(15- \\
98)\end{array}$ \\
\hline WOMAC & $\begin{array}{c}53.7 \\
(24.2- \\
81.8)\end{array}$ & $\begin{array}{c}69.1(37.5- \\
91.7)\end{array}$ & $\begin{array}{c}67.1 \\
(32.6- \\
94.7) \\
\end{array}$ & $\begin{array}{c}59.1(23.7 \\
80.8)\end{array}$ \\
\hline IKDC & $\begin{array}{c}36.4(13- \\
65.5)\end{array}$ & $\begin{array}{c}46.4(18.4- \\
71.3)\end{array}$ & $\begin{array}{c}41.3 \\
(14.9- \\
86.2)\end{array}$ & $\begin{array}{c}37.5(12- \\
78.2)\end{array}$ \\
\hline KOOS & $\begin{array}{l}49.7 \\
(20.8- \\
83.9)\end{array}$ & $\begin{array}{c}65 \text { (41.4- } \\
82.9)\end{array}$ & $\begin{array}{c}58.8 \\
(27.4-90\end{array}$ & $\begin{array}{c}51.1(22- \\
80.1\end{array}$ \\
\hline \multicolumn{5}{|c|}{ able 4. Group 3 (Ostenil Plus, OP), all scores. } \\
\hline $\begin{array}{c}\text { Ostenil } \\
\text { plus }\end{array}$ & Baseline & $\begin{array}{c}\text { After } 2 \\
\text { months }\end{array}$ & $\begin{array}{c}\text { After } 6 \\
\text { months }\end{array}$ & $\begin{array}{l}\text { After } 12 \\
\text { months }\end{array}$ \\
\hline VAS & $\begin{array}{c}68.9(50- \\
90)\end{array}$ & $\begin{array}{c}44.8(0- \\
100)\end{array}$ & $\begin{array}{c}55.5(10- \\
100)\end{array}$ & $\begin{array}{c}61.8(17- \\
100)\end{array}$ \\
\hline WOMAC & $\begin{array}{c}45.3(12.9- \\
73.4)\end{array}$ & $\begin{array}{c}67.3(24.2- \\
99)\end{array}$ & $\begin{array}{c}63.6(25- \\
94.7)\end{array}$ & $\begin{array}{c}58.7(22- \\
89.1)\end{array}$ \\
\hline IKDC & $\begin{array}{c}25.3(10.3- \\
43.7)\end{array}$ & $\begin{array}{c}40.2(21.8- \\
65.5)\end{array}$ & $\begin{array}{c}40.7(17.2- \\
75.9)\end{array}$ & $\begin{array}{c}35.8(13.1- \\
69.7)\end{array}$ \\
\hline KOOS & $\begin{array}{c}41(13.1- \\
62.5)\end{array}$ & $\begin{array}{c}58.7(19.6- \\
86.6)\end{array}$ & $\begin{array}{c}54.7(27.4- \\
90.5)\end{array}$ & $\begin{array}{c}46.3(17.3- \\
82.4)\end{array}$ \\
\hline
\end{tabular}

IKDC and KOOS scores between the three groups at baseline $(p>0.05)$. Two months after the last injection (Figure 2), there were statistical significant differences in CM Group when compared to AV and OP groups in VAS, WOMAC, KOOS and IKDC scores $\mathrm{p}<0.05$, even though we found improvement in all groups in all these parameters when compared to baseline values. There were high statistical significant differences $(\mathrm{p}<0.01)$ in CM Group 
The new treatment approach in knee osteoarthritis: Efficacy of Research Article cellular matrix combination of platelet rich plasma with hyaluronic acid versus two different types of hyaluronic acid $(\mathrm{HA})$

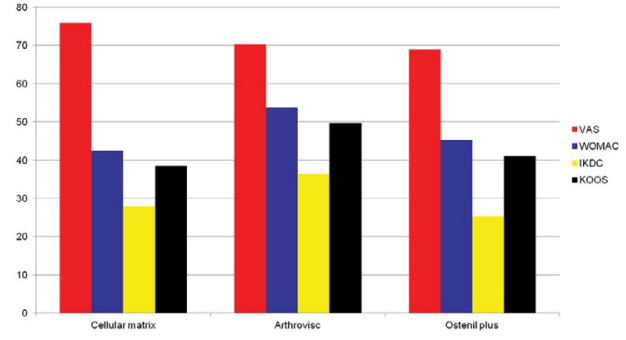

Figure 1. Baseline, all scores in all groups, p>0.05.

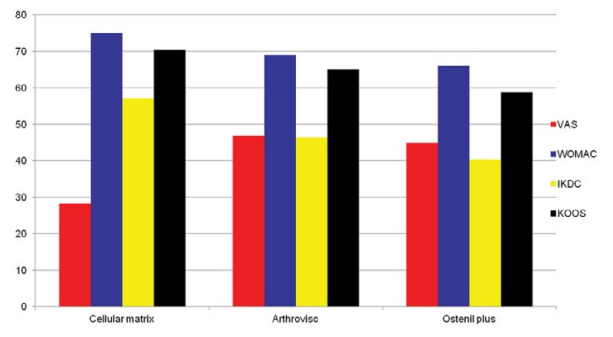

Figure 2. After 2 months all scores in all groups, $\mathrm{p}<0.05$.

when compared to $\mathrm{AV}$ and $\mathrm{OP}$ groups in VAS, WOMAC, KOOS and IKDC score 6 months after the last injection (Figure 3). On the other hand, in both groups treated with HA (AV and OP groups) we found deterioration in VAS, WOMAC, KOOS and IKDC score after 6 months. The effect of CM-PRP-HA therapy was persistent even 12 months after the last injection. After a period of one year follow up, high statistical significant differences $(\mathrm{p}<0.01)$ was observed in the CM group, when compared to $\mathrm{AV}$ and $\mathrm{OP}$ groups in VAS, WOMAC, KOOS and IKDC scores (Figure 4).

The special focus of this study was on the CM-PRP-HA therapy effects on cartilage thickness at 2, 6, and 12 months after the last IA injection as well as after HA IA injections. As foreseen, neither statistical significant differences, nor cartilage thickening, were seen in AV and OP groups 2, 6 and 12 months after the treatment ( $p>0.05$, data not shown). On the other hand, for patients treated with CM-PRP$\mathrm{HA}$, we found statistically significant $(\mathrm{p}<0.05)$ improvement in cartilage thickness already after 2 months and also after 6 and 12 months in medial compartment, and high statistically significant improvement $(\mathrm{p}<0.001)$ in lateral compartments (Table 5).

\section{Safety}

No single serious adverse events were reported in patient treated with CM-PRPHA combination. In 5 patients treated with $\mathrm{HA}, 2$ in AV group and 3 in OP group, mild

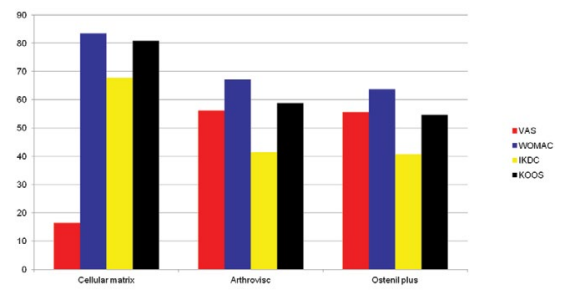

Figure 3. After 6 months, all scores in all groups, $p<0.01$.

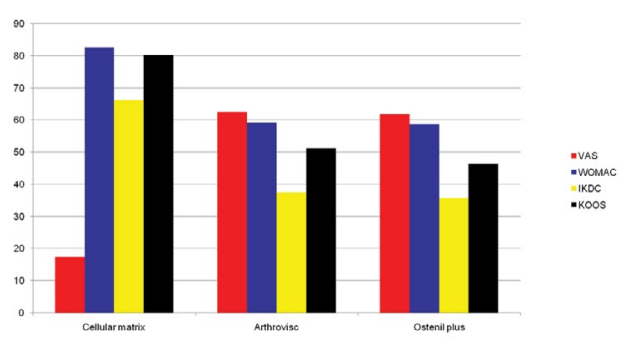

Figure 4. After 12 months, all scores in all groups, $p<0.01$.

\begin{tabular}{|c|c|c|c|c|c|}
\hline & Baseline & $\begin{array}{l}\text { After } 2 \\
\text { months }\end{array}$ & $\begin{array}{l}\text { After } 6 \\
\text { months }\end{array}$ & $\begin{array}{l}\text { After } 12 \\
\text { months }\end{array}$ & $\begin{array}{c}\text { ICC 95\% } \\
\mathrm{Cl}\end{array}$ \\
\hline LAT $^{* *}$ & $\begin{array}{c}1.5(0.5- \\
3)\end{array}$ & $\begin{array}{c}1.9(0.8- \\
3.1)\end{array}$ & $\begin{array}{c}2.1(1- \\
3.1)\end{array}$ & $\begin{array}{c}2.2(1.3- \\
3.5)\end{array}$ & $\begin{array}{c}0.93 \\
(0.84- \\
0.97)\end{array}$ \\
\hline MED* & $\begin{array}{c}1.6(0.7- \\
2.5)\end{array}$ & $\begin{array}{c}1.9(0.5- \\
3)\end{array}$ & $2(1-2.8)$ & $\begin{array}{c}2.1(1.3- \\
2.9)\end{array}$ & $\begin{array}{c}0.87 \\
(0.72- \\
0.94)\end{array}$ \\
\hline TRO & $\begin{array}{c}2.2(0.9- \\
3.5)\end{array}$ & $\begin{array}{c}2.4(1.2- \\
3.6)\end{array}$ & $\begin{array}{c}2.4(1.4- \\
3.5)\end{array}$ & $\begin{array}{c}2.3(1.5- \\
3.4)\end{array}$ & $\begin{array}{c}0.9 \text { (08.- } \\
0.96\end{array}$ \\
\hline
\end{tabular}

inflammatory reactions, with redness on treated spot, were recorded which lasted for a maximum of 12 hours.

\section{Discussion}

PRP, as one of the new therapeutic options for knee osteoarthritis, was compared to conservative HA treatment in several studies. One of the studies [15] dealt with comparison of the effect of PRP with two different types of HA. It was a prospective comparative study testing PRP against low molecular weight HA (LW$\mathrm{HA}$ ) and high molecular weight $\mathrm{HA}$ (HW-HA). There were 3 homogeneous groups of 50 patients each. After a follow-up period of 6 months better performance for VAS and WOMAC scores were found in the PRP group [15]. In another study [16], efficacy of single-spinning leukocyte-free PRP injection was compared to HA in 153 patients evaluated up to 6 months of follow-up. Contrary to the previous study the only parameter where a clear superiority of PRP was found, was 
the percentage of responders (patients with at least $50 \%$ of pain reduction) [16]. On the other hand, in several meta-analyses, it has been shown that PRP is superior to HA in pain management and improving mobility for patients suffering from knee osteoarthritis [17-24].

In our study, we show that therapeutic application of series of 3 CM-PRP-HA injections were superior to traditional HA therapy in all measured scores (WOMAC, IKDC and KOOS) as well as for Visual Analog Pain Scale. One of the contribution of our study was the longterm efficacy of CM-PRP-HA with a 12-month follow-up period, in comparison to both HA treated groups. Although improvement was recorded in all three groups after two months of follow-up, significant deterioration was detected in both HA treated groups after 6 and especially after 12 months of follow-up.

Synergistic effect of PRP an HA was demonstrated in many in vitro studies. Their different mechanism of action could modulate different aspects of osteoarthritis, affecting both sides of disease, visco-supplementation and treatment of secondary inflammation and degenerative changes [25]. An in vitro and OA animal model study from Chen et al. (14) supports this hypothesis. This study also suggested that chondrogenesis was induced more strongly by the PRP+HA combination than by PRP or HA only. Postponing the surgical procedure was the goal for many studies. Treatments with consecutive PRP and HA injections was able to reduce the pain and improve functional ability in patients with advance knee OA, and in some studies it helped to postpone knee surgery and arthroplasty [26,27]. Renevier et al. reported positive results with CM-PRP-HA treatment in a pilot multicenter French study with a long-term follow-up, after a series of three IA injections scheduled at day 0 , day 60 and day 180, that provided long-lasting benefits for half of the patients and avoiding surgery for almost $80 \%$ of them at four years [28]. According to all results CM-PRP-HA treatment maintain long lasting good clinical outcome for pain management and functional improvement of the knee. It could be used as well for traumatic cartilage pathologies as for patients with degenerative OA.

\section{Conclusion}

For the first time in literature, to our knowledge, we quantified in our study therapeutic effect of PRP and HA combination (prepared with the Cellular Matrix A-CP-HA device) on cartilage. With a very strong interobserver correlation rate coefficient, we show statistical significant thickening of the cartilage 2, 6 and 12 months after the end of CM-PRP-HA treatment on both lateral $(\mathrm{p}<0.05)$, and medial $(\mathrm{p}<0.01)$ compartments. With statistical significant improvement in all measured scores (WOMAC, IKDC, KOOS and VAS) at all follow-up visits in CM group when compared to both HA groups and statistical significant cartilage thickening, we can conclude that CM-PRP-HA might be one of the most potent and safe new therapeutic option for the treatment of knee osteoarthritis with Kellgren-Lawrence grade I to III, as well as a useful tool in postponing arthroplasty surgery, when it is necessary. For further investigations, we need larger prospective double-blind studies, with MRI quantification of CM-PRP-HA effects on cartilage. Taking all this in consideration, we are very close to believe that the future therapeutic option for osteoarthritis pathology will be combining therapeutic effects of Cellular Matrix CM-PRP-HA with bone marrow mesenchymal stem cells.

\section{Disclosure of Interest}

$\mathrm{BB}$ received consulting fees from Regen lab SA. The other authors declare that they have no competing interest.

\section{References}

1. Egloff C, Hugle T, Valderrabano V. Biomechanics and pathomechanisms of osteoarthritis. Swiss. Med. Wkly. 142, w13583 (2012).

2. Robinson DL, Kersh ME, Walsh NC et al. Mechanical properties of normal and osteoarthritic human articular cartilage. J. Mech. Behav. Biomed. Mater. 61, 96-109 (2016).

3. Jevsevar DS, Brown GA, Jones DL et al. The American Academy of Orthopaedic Surgeons evidence-based guideline on: Treatment of osteoarthritis of the knee (2nd edition). J. Bone. Joint. Surg. Am. 95(20), 1885-1886 (2013).

4. Zhang W, Nuki G, Moskowitz RW et al. OARSI recommendations for the management of hip and knee osteoarthritis: Part III: changes in evidence following systematic cumulative update of research published through. Osteoarthr. Cartil. 18(4), 476-499 (2010).

5. Recommendations for the medical management of osteoarthritis of the hip and knee: 2000 update. American College of Rheumatology Subcommittee on Osteoarthritis Guidelines. Arthritis. Rheum. 43(43), 1905-1915 (2000).

6. de Rezende MU, Gobbi RG. Drug therapy in knee osteoarthrosis. Rev. Bras. Ortop. 44(1), 1419 (2009). 
The new treatment approach in knee osteoarthritis: Efficacy of Research Article cellular matrix combination of platelet rich plasma with hyaluronic acid versus two different types of hyaluronic acid (HA)

7. Richmond J, Hunter D, Irrgang J et al. American Academy of Orthopaedic Surgeons clinical practice guideline on the treatment of osteoarthritis (OA) of the knee. J. Bone. Joint. Surg. Am. 92(4), 990-993 (2010).

8. Maricar N, Callaghan MJ, Felson DT et al. Predictors of response to intra-articular steroid injections in knee osteoarthritis-a systematic review. Rheumatology. 52(6), 1022-1032 (2013).

9. Pourcho AM, Smith J, Wisniewski SJ et al. Intraarticular platelet-rich plasma injection in the treatment of knee osteoarthritis: Review and recommendations. Am. J. Phys. Med. Rehabil. 93(11), S108-S121 (2014).

10. Smyth NA, Murawski CD, Fortier LA et al. Plateletrich plasma in the pathologic processes of cartilage:review of basic science evidence. Arthroscopy. 29(8), 1399-1409 (2013).

11. Tietze DC, Geissler K, Borchers J. The effects of platelet-rich plasma in the treatment of largejoint osteoarthritis: A systematic review. Phys. Sportsmed. 42(2), 27-37 (2014).

12. Nazempour A, Van Wie BJ. Chondrocytes, mesenchymal stem cells, and their combination in articular cartilage regenerative medicine. Ann. Biomed. Eng. 44(5), 1325-1354 (2016).

13. Foster TE, Puskas BL, Mandelbaum BR et al. Platelet-rich plasma: From basic science to clinical applications. Am. J. Sports. Med. 37(11), 2259-2272 (2009).

14. Chen WH, Lo WC, Hsu WC et al. Synergistic anabolic actions of hyaluronic plasma and platelet-rich plasma on cartilage regeneration in osteoarthritis therapy. Biomaterials. 35, 9599-9607 (2014).

15. Kon E, Mandelbaum B, Buda R et al. Plateletrich plasma intra-articular injection versus hyaluronic acid viscosupplementation as treatments for cartilage pathology: from early degeneration to osteoarthritis. Arthroscopy. 27(11), 1490-1501 (2011).

16. Sanchez M, Fiz N, Azofra J et al. A randomized clinical trial evaluating plasma rich in growth factors (PRGF-Endoret) versus hyaluronic acid in the short-term treatment of symptomatic knee osteoarthritis. Arthroscopy. 28(8), 1070-1078 (2012).

17. Laudi AB, Bakker EW, Rekers et al. Efficacy of platelet rich plasma injections in osteoarthritis of the knee: a systematic review and meta-analysis. Br. J. sports. Med. (2014).

18. Laver L, Marom N. PRP for degenerative cartilage disease: A systematic review of clinical studies. Cartilage. (2016).

19. Dai WL, Zhou H. Efficacy of platelet rich plasma in the threatment of knee osteoarthritis: A meta- analysis of randomized controlled trials. Arthroscopy. 33(3), 659-670 (2017).

20. Meheux CJ, McCullox PC, Linter DM et al. Efficacy of intra-articular platelet rich plasma injections in knee osteoarthritis: A systematic review. Arthroscopy. 32(3), 495-505 (2016).

21. Lai LP, Stitik TP, Foye PM et al. Use of platelet rich plasma in intra articular knee injections for osteoarthritis: A systematic review. PM. R. ( 2015 ).

22. Khoshbin A, Leroux T, Wasserstein D et al. The efficacy of platelet rich plasma in the treatment of symptomatic knee osteoarthritis: A systematic review with quantitative synthesis. Arthroscopy. 29(12), 2037-2048 (2013).

23. Chang KV, Hung CY, Aliwarga F et al. Comparative effectiveness of platelet rich plasma injections for treating knee joint cartilage degenerative pathology: A systematic review and meta-analysis. Arch. Phys. Med. Rehabil. 95(3), 562-575 (2014).

24. Campbell KA, Saltzman BM, Mascarenhas R et al. Does intra- articular platelet rich plasma injections provide clinically superior outcomes compared with other therapies in the treatment of knee osteoarthritis? A systematic review of overlapping meta-analysis. Arthroscopy. 31(11), 2213-2221 (2015).

25. Chen CPC, Cheng CH, Hsu CC et al. The influence of platelet rich plasma on synovial fluid volumes, protein concentrations, and secerity of pain in patients with knee osteoarthritis. Exp. Gerontol. 93, 68-72 (2017).

26. Saturveithan C, Premganesh G, Fakhrizzaki S et al. Intra-articular hyaluronic acid (HA) and platelet rich plasma ( PRP) injections versus hyaluronic acid (HA) injections in grade III and IV knee osteoarthritis $(\mathrm{OA})$ patients: A retrospective study on functional outcome. $45^{\text {th }}$ Malasyan Orthopedeic Association (2015).

27. Chen SH, Khuan TS, Kao MJ et al. Clinical effectiveness in severe knee osteoarthritis after intra-articular platelet rich plasma therapy in association with hyaluronic acid injection: Three case reports. Clin. Interv. Aging. 11, 1213-1219 (2016).

28. Renevier JL, Marc JF, Adam P et al. "Cellular Matrix TM PRP-HA": A new treatment option with platelet-rich plasma and hyaluronic acid for patients with osteoarthritis having had an unsatisfactory clinical response to hyaluronic acid alone: Results of a pilot multicenter French study with long-term follow-up. Int. J. Clin. Rheumatol. 13(4), 226-229 (2018). 